\title{
Management of medical complications after pneumonectomy
}

\author{
Alessio Campisi ${ }^{1}$, Luca Bertolaccini ${ }^{2}$, Jizhuang Luo $^{3}$, Franco Stella ${ }^{1}$, Wentao Fang ${ }^{3}$ \\ ${ }^{1}$ Thoracic Surgery Unit, Department of Thoracic Diseases, G.B. Morgagni-L. Pierantoni Hospital, Forlì, Italy; ${ }^{2}$ Department of Thoracic Surgery, \\ European Institute of Oncology IRCCS, Milan, Italy; ${ }^{3}$ Department of Thoracic Surgery, Shanghai Chest Hospital, Shanghai Jiao Tong University, \\ Shanghai 200030, China \\ Contributions: (I) Conception and design: A Campisi, W Fang; (II) Administrative support: W Fang, F Stella; (III) Provision of study materials or \\ patients: A Campisi, L Bertolaccini; (IV) Collection and assembly of data: A Campisi; (V) Data analysis and interpretation: A Campisi, W Fang; (VI) \\ Manuscript writing: All authors; (VII) Final approval of manuscript: All authors. \\ Correspondence to: Alessio Campisi. Thoracic Surgery Unit, Department of Thoracic Diseases, G.B. Morgagni-L. Pierantoni Hospital, Forlì, Italy. \\ Email: alessio.campisi@studio.unibo.it.
}

\begin{abstract}
Pneumonectomy is still a surgical alternative for some patients with advanced non-small cell lung cancer. However, it is associated with a significant incidence of perioperative morbidity and mortality, far higher than other pulmonary resections, and therefore should only be considered when a more conservative resection is not technically feasible or oncologically adequate. Careful preoperative evaluation of patients' functional status is mandatory and stringent postoperative care with early diagnosis and appropriate management is crucial to minimize the risk of medical complications, to reduce mortality, and to improve quality of life of pneumonectomy patients.
\end{abstract}

Keywords: Medical complications; pneumonectomy; non-small cell lung cancer

Received: 09 October 2019; Accepted: 25 October 2019; Published: 10 April 2020.

doi: $10.21037 /$ shc.2019.10.10

View this article at: http://dx.doi.org/10.21037/shc.2019.10.10

\section{Introduction}

"The best treatment of postoperative complications is prevention". This motto is useful for any surgery but particularly, for pneumonectomy due to its high morbidity and mortality rates $(1,2)$. From a didactic point of view, postoperative complications after pneumonectomy can be divided based on time of occurrence or based on their mechanisms. Thus, they are usually defined as early and late complications or medical and surgical complications. Anyhow, the same complication can be treated in different manners; therefore, it is essential they are early identified and correctly managed. Moreover, careful preoperative patient evaluation will help to mitigate most of commonly encountered postoperative complications.

Ninety years have passed since the first successful pneumonectomy in 1933 (3), yet its mortality remains significantly high, although in a tendency of declining $(4,5)$. This decrease is attributed to a multidisciplinary team approach, careful patient selection, increased awareness of early signs of complications and improvement in the treatment provided to these conditions.

The scope of this article is to take into consideration the most common post-pneumonectomy medical complications and evaluate the best way to manage them.

\section{Methods}

The authors carried out a search in the PubMed database using the following strategy: ((("pneumonectomy"[Title/ Abstract]) AND (("complication") OR "complications")) AND "cancer") AND (("management") OR "treatment")). Only English-language articles published between January 1, 2004, and August 31, 2019 were included. References of relevant articles were also manually searched to identify potentially eligible articles. A second part of the search consisted of the analysis of review articles published about each complication alone. 


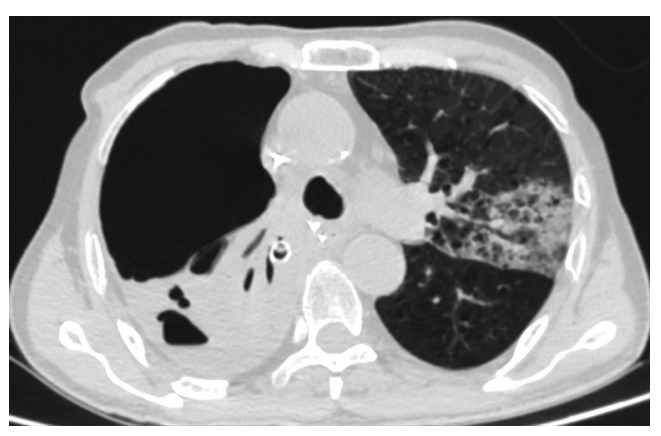

Figure $1 \mathrm{CT}$ scan showing bacterial pneumonia of the left upper lobe after right pneumonectomy.

\section{Results}

Four-hundred-and-sixty-five papers were found in literature search. After a manual review of title and abstract and/or full text of each citation, the authors screened 35 papers. Among these studies, the most common medical complications experienced after pneumonectomy are atrial fibrillation, pneumonia, and vocal cord paralysis (6-9). Another critical complication to consider is pulmonary embolism (PE). Finally, post-pneumonectomy pulmonary edema, a rare but life-threatening condition, deserves special mention.

\section{Arrbythmia}

In most of the series, arrhythmia was found to be the most common complication after thoracic surgery, especially after pneumonectomy $(6,10)$. Its incidence varies from 11 to $47 \%$, usually being supraventricular in origin (most often atrial fibrillation), and occurring in the first $72 \mathrm{~h}$ after surgery. Multiple risk factors have been identified as predisposing to arrhythmia, including cardiopulmonary diseases (e.g., ischaemic heart disease, heart failure, preoperative arrhythmia and hypertension), increasing age, male gender, surgical intervention method (right pneumonectomy and pericardial opening), and blood transfusions (11). Mixed results cast doubt on the beneficial effect of video-thoracoscopy (11). Concerning prophylactic medication, no consensus was found regarding treatment protocol or patient selection $(10,12)$. Meanwhile pharmacological control of cardiac rate and restore of sinus rhythm is well-known (12). Amiodarone has been widely employed in the management of atrial fibrillation after cardiothoracic surgery, because of its capability to lower the heart rate and to restore the sinus rhythm (13). But its use has also been questioned because of its potential acute lung damage effect (14). Calcium channel antagonists, in particular diltiazem, are considered the first choice because of their activity in heart rate control, with no risk of bronchial spastic effect of beta-blockers (15). Although seldom necessary, synchronised cardioversion remains the treatment of choice in severe cardiac compromise because of tachycardia.

\section{Vocal cord paralysis}

According to Alloubi et al. (6), recurrent laryngeal nerve damage and subsequent vocal cord paralysis is the second most common complication after pneumonectomy. Due to its anatomical position, it happens more often on the left side. The clinical scenario may vary from weak and whispery voice to aspiration, and thus should not be underestimated. Treatment involves determining the extent of injury and whether the injury is transient or permanent. Fiberoptic study allows for a more precise assessment of laryngeal function. As already mentioned, the best treatment is prevention. "No-touch" technique has been advised, and avoiding of excessive coagulation recommended during lymphadenectomy of the aortopulmonary window (16). Treatment may be conservative or surgical. In our experience, voice building exercises can improve the strength and bulk of the vocal muscles, allowing closure of the vocal folds, leading to increased endurance in speaking and exercising. Medialization laryngoplasty with implant material (autologous fat, Gelfoam, collagen, or polytetrafluoroethylene) may help decrease the risk of aspiration (16).

\section{Pneumonia}

Pneumonia is one of the most common complications after pneumonectomy (Figure 1), and this is particularly true after neoadjuvant chemotherapy or radiotherapy (17). It may lead to respiratory failure, cardiac events, or even death (18). According to Schussler et al. (18), bacterial infection is generally responsible for early hospital-acquired pneumonia, and the most frequently identified species are H. Influenzae (41.7\%), S. pneumoniae (25\%), Pseudomonas species $(25 \%)$ etc. From our review, risk factors include advanced age, male gender, preoperative hospital stay, immunocompromised state, associated respiratory diseases, smoking, regular alcohol intake and atelectasis. Again, prevention is the best treatment. Chest physiotherapy, 
frequent spirometry exercises, early ambulation, expectorants and optimal pain control are the mainstays of prevention. Anyhow, pneumonia may occur, and when clinically suspected, broad-spectrum antibiotic therapy should be started based on sputum culture. Moreover, respiratory physiotherapy should be carried on together with respiratory treatments and adequate hydration.

\section{$P E$}

$\mathrm{PE}$ is a severe and life-threatening complication with an incidence of up to $7 \%$ after pneumonectomy (19). Some authors have reported a $50 \%$ mortality rate from $\mathrm{PE}$ after pneumonectomy (20), but it may also be as low as $2-10 \%$ in patients with timely diagnosis and intervention (21). Fortunately, its incidence is progressively reduced thanks to comprehensive anticoagulant prevention, better surgical techniques, appropriate management in perioperative period and early ambulation, etc. Multiple risk factors have been described starting from the Virchow's triad of pathogenesis of thrombosis. These include non-surgical risks like old age, previous history of venous thromboembolism, active tumour, nerve diseases, natural or acquired thrombophilia, hormone replacement therapy and oral contraception, obesity, smoking habits and systemic hypertension or metabolic syndrome, etc. (22). Some specific risk factors are associated with pulmonary resections and, mainly, with pneumonectomy. Damage to the walls of the blood vessels during operation is associated with clot formation and development of PE. Right decubitus position has been linked to being a predisposing factor for PE due to decrease in venous velocity of the right femoral vein and iliac compression syndrome (23). According to Kwek et al. (24), length of pulmonary artery stump might predispose to thrombus formation and cross embolisation to the contralateral artery.

Furthermore, Işik et al. (25) showed that thrombus formation in the pulmonary artery is more likely to occur when closure of the stump is made with the transfixation ligature technique compared with the continuous suture technique, following to the damage to the intimal surface. Regardless of its aetiology, timely diagnosis will definitely improve the outcome after PE; anyhow, diagnosing acute $\mathrm{PE}$ after pulmonary resections has presented with some difficulties, as its clinical signs and symptoms such as chest pain, shortness of breath, tachycardia and decreased blood oxygen saturation are sometimes hard to differentiate from those related to surgical trauma per se, or cardiac problems such as myocardial infarction. The European Society of Cardiology classified patients with PE into high risk and non-high-risk groups; the latter one subdivided into intermediate-risk and low-risk groups (22). In highrisk patients with suspicion of $\mathrm{PE}$, computed tomographic pulmonary angiography is the gold standard for diagnosis. Prevention, like in all the other diseases, is better than its treatment. The use of intermittent pneumatic compression has been strongly supported by Nagahiro et al. (26). Use of anticoagulant therapy has been worried to cause more bleeding and epidural hematoma. In our experience and according to Costantino et al. (27) and Erkens et al. (28), use of low molecular weight heparin is safe and has lower chance of causing major bleeding compared to unfractionated heparin.

Treatment approach also differs in high-risk and non-high-risk patients. In the former group, the use of anticoagulant therapy, thrombolytic therapy and oxygen inhalation therapy or in selected cases, mechanical ventilation has significantly improved the outcome. No difference was found in the risk of bleeding and the effectiveness between low molecular weight heparin and unfractionated heparin (29). The use of thrombolysis treatment is still under debate for a high risk of bleeding, especially in the early postoperative period. Different studies and case reports (30) have tried to figure out the optimal timing of the use of thrombolysis for safety. Kameyama et al. performed thrombolysis $3.5 \mathrm{~h}$ later after surgery with no significant complications (31). Anyhow, the controversy is far from being solved.

Another option for patients with absolute contraindications of thrombolysis or unimproved hemodynamic status by thrombolysis may be surgical intervention (embolectomy), but it has intrinsic mortality (32). At the moment, indication of pulmonary arterial embolectomy has spread to patients with right ventricular failure but without severe shock. Anyhow, it is contraindicated when there is multiple organ failure due to massive embolism and risk of massive bleeding during operation (33). Another treatment for these patients is inferior vena cava filter placement, but no beneficial effect has been proved up till now (34).

Non high-risk patients have a better short-term prognosis compared to the high-risk group. Anticoagulation therapy should be performed immediately, while mixed data from trials showed no clinical benefits from thrombolysis treatment to this group of patients (35). 


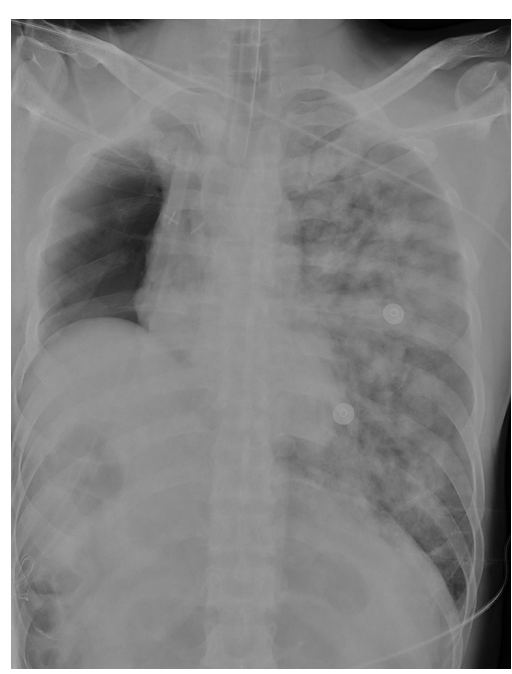

Figure 2 Chest X-ray showing diffuse opacities on the left lung, in a patient who underwent right pneumonectomy.

\section{Post-pneumonectomy pulmonary edema}

Since its first description in 1942 (36) and its definition as a distinct clinical entity in 1984 (37), post-pneumonectomy pulmonary edema has been primarily studied. It is a life-threatening condition, occurring in $4-7 \%$ (38) of pneumonectomy patients with a mortality rate up to $64 \%$, despite recent advances in modern perioperative care (39). Clinically, it is characterised by acute onset of dyspnea, rales and diffuse chest $\mathrm{X}$-rays opacities (Figure 2), with exclusion of other causes (infections, left ventricular dysfunction). It has been demonstrated that post-pneumonectomy pulmonary edema has a multifactorial aetiology, associated with anaesthesia, surgery or postoperative management, respectively (39). Some of them may be modified, like mechanical ventilation with high volume or high oxygen concentration, mediastinal shift due to use of non-balanced drainage system and fluid overload, while others are immutable, like side of the surgery (right pneumonectomy is associated with higher risk of post-pneumonectomy edema due to contralateral lymphatic drainage disruption) $(40,41)$. Treatment is merely supportive. Mechanical ventilation, if needed, should be set similar to ARDS patients, with a tidal volume of $6 \mathrm{~mL} / \mathrm{kg}$ and plateau pressures less than $30 \mathrm{cmH}_{2} \mathrm{O}(42)$. In case of pulmonary hypertension, nitric oxide has been already proven to be effective in improving oxygenation (43). Finally, in severe, refractory cases, extracorporeal membrane oxygenation (ECMO) is helpful (44).

\section{Conclusions}

Despite the progress in oncological therapies which has been achieved in recent years, pneumonectomy remains a necessary and sometimes unavoidable procedure in surgical treatment for lung cancer. Anyhow, it carries a higher risk of early and late complications, as compared to other types of pulmonary resections. Therefore, before performing a pneumonectomy, all options for lung-sparing procedures, including sleeve resections should be evaluated. When pneumonectomy is mandatory, a multidisciplinary panel of clinicians should be aware of the risk and high probability of complications inherent to this procedure. Existing literature suggest that patients for whom pneumonectomy is considered should be evaluated very carefully in the preoperative period and should be monitored and appropriately examined in the postoperative phase to timely identify and treat any complication that may occur.

\section{Acknowledgments}

Funding: None.

\section{Footnote}

Provenance and Peer Review: This article was commissioned by the editorial office, Shanghai Chest for the series "The Role of Pneumonectomy in Thoracic Surgery in The Third Millennium". The article has undergone external peer review.

Conflicts of Interest: All authors have completed the ICMJE uniform disclosure form (available at http://dx.doi. org/10.21037/shc.2019.10.10). The series "The Role of Pneumonectomy in Thoracic Surgery in The Third Millennium" was commissioned by the editorial office without any funding or sponsorship. LB served as the unpaid Guest Editor of the series and serves as an unpaid editorial board member of Shanghai Chest from Aug 2019 to Jul 2021. WF served as an unpaid Executive Editor-in-Chief of Shanghai Chest. The authors have no other conflicts of interest to declare.

Ethical Statement: The authors are accountable for all aspects of the work in ensuring that questions related to the accuracy or integrity of any part of the work are appropriately investigated and resolved.

Open Access Statement: This is an Open Access article 
distributed in accordance with the Creative Commons Attribution-NonCommercial-NoDerivs 4.0 International License (CC BY-NC-ND 4.0), which permits the noncommercial replication and distribution of the article with the strict proviso that no changes or edits are made and the original work is properly cited (including links to both the formal publication through the relevant DOI and the license). See: https://creativecommons.org/licenses/by-nc-nd/4.0/.

\section{References}

1. Kim DJ, Lee JG, Lee CY, et al. Long-term survival following pneumonectomy for non-small cell lung cancer: clinical implications for follow-up care. Chest 2007;132:178-84.

2. Shapiro M, Swanson SJ, Wright CD, et al. Predictors of major morbidity and mortality after pneumonectomy utilizing the Society for Thoracic Surgeons General Thoracic Surgery Database. Ann Thorac Surg 2010 Sep;90:927-34; discussion 934-5.

3. Graham EA, Singer JJ. Landmark article Oct 28, 1933. Successful removal of an entire lung for carcinoma of the bronchus. By Evarts A. Graham and J. J. Singer. JAMA 1984;251:257-60.

4. Krasna MJ, Gamliel Z, Burrows WM, et al. Pneumonectomy for lung cancer after preoperative concurrent chemotherapy and high-dose radiation. Ann Thorac Surg 2010;89:200-6.

5. Abby White, Suden Kucukak, Raphael Bueno, et al. Pneumonectomy is safe and effective for non-small cell lung cancer following induction therapy. J Thorac Dis 2017;9:4447-53.

6. Alloubi I, Jougon J, Delcambre F, et al. Early complications after pneumonectomy: retrospective study of 168 patients. Interact Cardiovasc Thorac Surg 2010;11:162-5.

7. Sugarbaker DJ, Jaklitsch MT, Bueno R, et al. Prevention, early detection, and management of complications after 328 consecutive extrapleural pneumonectomies. J Thorac Cardiovasc Surg 2004;128:138-46.

8. Zellos L, Jaklitsch MT, Al-Mourgi MA, et al. Complications of extrapleural pneumonectomy. Semin Thorac Cardiovasc Surg 2007;19:355-9.

9. Sugarbaker DJ, Haywood-Watson RJ, Wald O. Pneumonectomy for Non-Small Cell Lung Cancer. Surg Oncol Clin N Am 2016;25:533-51.

10. Vaporciyan AA, Correa AM, Rice DC, et al. Risk factors associated with atrial fibrillation after noncardiac thoracic surgery: analysis of 2588 patients. J Thorac Cardiovasc
Surg 2004;127:779-86.

11. Lee SH, Ahn HJ, Yeon SM, et al. Potentially modifiable risk factors for atrial fibrillation following lung resection surgery: a retrospective cohort study. Anaesthesia 2016;71:1424-30.

12. Ai D, Xu G, Feng L, et al. Dexmedetomidine does not reduce atrial fibrillation after lung cancer surgery. $\mathrm{J}$ Cardiothorac Vasc Anesth 2015 Apr;29:396-401.

13. Martinez EA, Bass EB, Zimetbaum P, et al. Pharmacologic control of rhythm: American College of Chest Physicians guidelines for the prevention and management of postoperative atrial fibrillation after cardiac surgery. Chest 2005; 128:48S-55S.

14. Handschin AE, Lardinois D, Schneiter D, et al. Acute amiodarone-induced pulmonary toxicity following lung resection. Respiration 2003;70:310-2.

15. Amar D, Roistacher N, Rusch VW, et al. Effects of diltiazem prophylaxis on the incidence and clinical outcome of atrial arrhythmias after thoracic surgery. J Thorac Cardiovasc Surg 2000;120:790-8.

16. Krasna MJ, Forti G. Nerve injury: injury to the recurrent laryngeal, phrenic, vagus, long thoracic, and sympathetic nerves during thoracic surgery. Thorac Surg Clin 2006;16:267-75, vi.

17. Cerfolio RJ, Bryant AS, Spencer SA, et al. Pulmonary resection after high-dose and low-dose chest irradiation. Ann Thorac Surg 2005 Oct;80:1224-30; discussion 1230.

18. Schussler O, Alifano M, Dermine H, et al. Postoperative pneumonia after major lung resection. Am J Respir Crit Care Med 2006;173:1161-9.

19. Mason DP, Quader MA, Blackstone EH, et al. Thromboembolism after pneumonectomy for malignancy: an independent marker of poor outcome. J Thorac Cardiovasc Surg 2006;131:711-8.

20. Sakuragi T, Sakao Y, Furukawa K, et al. Successful management of acute pulmonary embolism after surgery for lung cancer. Eur J Cardiothorac Surg 2003;24:580-7.

21. Nikolaou K, Thieme S, Sommer W, et al. Diagnosing pulmonary embolism: new computed tomography applications. J Thorac Imaging 2010;25:151-60.

22. Torbicki A, Perrier A, Konstantinides S, et al. Guidelines on the diagnosis and management of acute pulmonary embolism: the Task Force for the Diagnosis and Management of Acute Pulmonary Embolism of the European Society of Cardiology (ESC). Eur Heart J 2008;29:2276-315.

23. Nagahiro I, Watanuki Y, Sato S, et al. Venous velocity of the right femoral vein decreases in the right lateral 
decubitus position compared to the supine position: a cause of postoperative pulmonary embolism? Acta Med Okayama 2007;61:57-61.

24. Kwek BH, Wittram C. Postpneumonectomy pulmonary artery stump thrombosis: CT features and imaging followup. Radiology 2005;237:338-41.

25. Işik F, Kara M, Tunçögür B, et al. Significance of ligature technique on the formation of pulmonary artery stump thrombosis in a canine model. Acta Chir Belg 2005;105:203-6.

26. Nagahiro I, Andou A, Aoe M, et al. Intermittent pneumatic compression is effective in preventing symptomatic pulmonary embolism after thoracic surgery. Surg Today 2004;34:6-10.

27. Costantino G, Ceriani E, Rusconi AM, et al. Bleeding risk during treatment of acute thrombotic events with subcutaneous LMWH compared to intravenous unfractionated heparin; a systematic review. PLoS One 2012;7:e44553.

28. Erkens PM, Prins MH. Fixed dose subcutaneous low molecular weight heparins versus adjusted dose unfractionated heparin for venous thromboembolism. Cochrane Database Syst Rev 2010: CD001100.

29. Prandoni P, Carnovali M, Marchiori A; Galilei Investigators. Subcutaneous adjusted-dose unfractionated heparin vs fixed-dose low-molecular-weight heparin in the initial treatment of venous thromboembolism. Arch Intern Med 2004;164:1077-83.

30. Molina JE, Hunter DW, Yedlicka JW, et al. Thrombolytic therapy for postoperative pulmonary embolism. Am J Surg 1992;163:375-80; discussion 380-1.

31. Kameyama K, Huang CL, Liu D, et al. Pulmonary embolism after lung resection: diagnosis and treatment. Ann Thorac Surg 2003;76:599-601.

32. Stein PD, Alnas M, Beemath A, et al. Outcome of pulmonary embolectomy. Am J Cardiol 2007;99:421-3.

33. Meneveau N, Séronde MF, Blonde MC, et al. Management of unsuccessful thrombolysis in acute massive pulmonary embolism. Chest 2006;129:1043-50.

34. Kearon C, Kahn SR, Agnelli G, et al. Antithrombotic

doi: $10.21037 /$ shc. 2019.10 .10

Cite this article as: Campisi A, Bertolaccini L, Luo J, Stella F, Fang W. Management of medical complications after pneumonectomy. Shanghai Chest 2020;4:13. therapy for venous thromboembolic disease:

American College of Chest Physicians Evidence-

Based Clinical Practice Guidelines (8th Edition). Chest 2008;133:454S-545S.

35. Wan S, Quinlan DJ, Agnelli G, et al. Thrombolysis compared with heparin for the initial treatment of pulmonary embolism: a meta-analysis of the randomized controlled trials. Circulation 2004;110:744-9.

36. Gibbon JH, Gibbon MH. Experimental pulmonary edema following lobectomy and plasma infusions. Surgery 1942;12:694-704.

37. Zeldin RA, Normandin D, Landtwing D, et al. Postpneumonectomy pulmonary edema. J Thorac Cardiovasc Surg 1984;87:359-65.

38. Parquin F, Marchal M, Mehiri S, et al. Postpneumonectomy pulmonary edema: analysis and risk factors. Eur J Cardiothorac Surg 1996;10:929-32; discussion 933.

39. Chau EH, Slinger P. Perioperative fluid management for pulmonary resection surgery and esophagectomy. Semin Cardiothorac Vasc Anesth 2014;18:36-44.

40. Alvarez JM, Tan J, Kejriwal N, et al. Idiopathic postpneumonectomy pulmonary edema: hyperinflation of the remaining lung is a potential etiologic factor, but the condition can be averted by balanced pleural drainage. J Thorac Cardiovasc Surg 2007;133:1439-47.

41. Alvarez JM, Panda RK, Newman MA, et al. Postpneumonectomy pulmonary edema. J Cardiothorac Vasc Anesth 2003;17:388-95.

42. Villeneuve PJ, Sundaresan S. Complications of pulmonary resection: postpneumonectomy pulmonary edema and postpneumonectomy syndrome. Thorac Surg Clin 2006;16:223-34.

43. Della Rocca G, Coccia C. Nitric oxide in thoracic surgery. Minerva Anestesiol 2005;71:313-8.

44. Dünser M, Hasibeder W, Rieger M, et al. Successful therapy of severe pneumonia-associated ARDS after pneumonectomy with ECMO and steroids. Ann Thorac Surg 2004;78:335-7. 